\title{
Stigma Resistance and Its Associated Factors among People with Bipolar Disorder at Amanuel Mental Specialized Hospital, Addis Ababa, Ethiopia
}

\author{
Nigus Alemnew Engidaw ${ }^{D},{ }^{1}$ Eyosiyas Yeshialem Asefa ${ }^{D},{ }^{1}$ Zelalem Belayneh $\mathbb{D}^{D},{ }^{2}$ \\ and Abate Dargie Wubetu (iD) \\ ${ }^{1}$ College of Health Sciences, Debre Berhan University, Debre Berhan, Ethiopia \\ ${ }^{2}$ Department of Psychiatry, College of Health and Medical Science, Dilla University, Dilla, Ethiopia
}

Correspondence should be addressed to Nigus Alemnew Engidaw; nigusalemnew2014@gmail.com

Received 8 June 2020; Revised 31 August 2020; Accepted 18 September 2020; Published 26 September 2020

Academic Editor: Marcin Rzeszutek

Copyright (c) 2020 Nigus Alemnew Engidaw et al. This is an open access article distributed under the Creative Commons Attribution License, which permits unrestricted use, distribution, and reproduction in any medium, provided the original work is properly cited.

\begin{abstract}
Background. Stigma resistance is the capacity to cope and remain unaffected by mental illness stigmatization. In bipolar patients, having low stigma resistance may result in a higher internalized stigma, low self-esteem, and poor treatment outcome. In Ethiopia, the prevalence of stigma resistance among bipolar patients is not well known. Therefore, this study is aimed at assessing the prevalence of stigma resistance and its associated factors among bipolar patients at Amanuel Mental Specialized Hospital, Addis Ababa, Ethiopia. Method. An institutional-based cross-sectional study was conducted from May $8^{\text {th }}$ to June $14^{\text {th }}$, 2016, at Amanuel Mental Specialized Hospital. The study participants were selected using a systematic random sampling technique. The stigma resistance subscale of the internalized stigma of mental illness was used to measure stigma resistance. Bivariable and multivariable logistic regression was computed to identify factors associated with stigma resistance. Accordingly, variables with $P$ values of less than 0.05 were considered as statistically significant predictors of stigma resistance with a $95 \%$ confidence interval. Results. In this study, 418 participants completed the interview with a response rate of $98.8 \%$. The prevalence of low stigma resistance was $56.9 \%(95 \% \mathrm{CI}=51.9-61.6 \%)$. Being unemployed $(\mathrm{AOR}=1.65 ; 95 \% \mathrm{CI}=1.35-1.87)$, high internalized stigma $(\mathrm{AOR}=3.04 ; 95 \% \mathrm{CI}=1.83-5.05)$ and low self-esteem $(\mathrm{AOR}=2.13 ; 95 \% \mathrm{CI}=1.72-6.76)$ were significantly associated with low stigma resistance. Conclusions and Recommendation. More than half of the bipolar patients attending the Amanuel Mental Specialized Hospital had low stigma resistance. Therefore, stigma reduction programs have focused on improving self-esteem and reducing internalized stigma to increase their stigma resistance. Mental health information dissemination regarding community support and reengagement of people with bipolar disorder is highly recommended.
\end{abstract}

\section{Background}

Bipolar disorder (BD) is one of the most common, severe, disabling, and chronic mental disorders. It is manifested by manic, hypomanic, or major depressive episodes $[1,2]$. According to the World Health Organization (WHO) report, the global burden of disease and lifetime risk of $\mathrm{BD}$ are $2.6 \%$ and $7.8 \%$, respectively $[3,4]$. BD has an enormous and devastating social, economic, and health impact on sufferers and their families $[5,6]$. Since this disorder is chronic, severe, and episodic by its nature, it has been shown to be related with unemployment, low productivity, poor social functioning, poor quality of life, disability, marital failure, high treatment costs, significant family burden, and poor quality of life [7-9]. Because of its relapsing nature, disability, and negative attitude of the society towards mental disorders, $\mathrm{BD}$ is also associated with stigma $[10,11]$.

Stigma is a multidimensional construct that involves feelings, attitudes, and behaviors. It encompasses three main constituents: negative stereotypes, prejudice, and discrimination [12]. Stigma is also a common and frequent burden of individuals with severe psychiatric disorders, their families, 
and caregivers [13-17]. The reactions to stigma by people with mental illness vary. Some people become energized and empowered (stigma resistance), few remain indifferent and unaffected, while others internalize stigma [18]. Internalized stigma is the process of applying negative stereotypes and stigmatizing attitudes to oneself and may exhibit behaviors like secrecy and withdrawal to cope with this discrimination [19]. If there is a high internalized stigma, stigma resistance (SR) will be low. Developing matured coping strategies such as psychological resilience and having better stigma resistance abilities are very important to tackle internalized stigma $[20,21]$.

Resilience has been conceptualized as "the capacity of a dynamic system to withstand or recover from significant challenges that threaten its stability, viability or development" [22]. Accordingly, resilience has been suggested to be relevant for coping with mental illness [23]. A previous study has shown that there is a positive correlation between stigma resistance and resilience [24]. SR is the capacity to resist, counteract, or remain unaffected by mental illness stigmatization [25]. It is a continuous and active process of using one's experiences, skills, and knowledge to develop an optimistic identity toward mental illness. Theoretical work on SR suggests that resisting stigma has an important role in fighting internalized stigma, facilitating the recovery from psychiatric illness, adherence, promoting their self-esteem, empowerment, quality of life, functionality, and community reengagement $[7,9$, $26,27]$. In previous studies, cut-off point at 2.5 and above on the mean item score of the SR subscale was used to define moderate to high (referred to as "high") stigma resistance and less than 2.5 for low stigma resistance $[9,28]$. Despite its clinical importance and applicability, the SR of people with $\mathrm{BD}$ is not still well addressed in clinical settings and community affairs. In some western and Asian nations, there are few studies reporting the level and predictors of SR among people with BD [7-9]. For example, a study conducted at 13 European countries among people with $\mathrm{BD}$ or depression reported that the level of SR was 59.7\% [7]. An Iranian study reported that the level of SR was 57.49\% [29]. Studies conducted in Turkey and northern India also showed that the level of SR was found to be $62.2 \%$ and $28.6 \%$, respectively [30]. Some studies have shown that the presence of traditional and supernatural beliefs about the cause of mental illness is related with stigmatizing attitudes and discrimination. For example, a study in Nigeria stated that subjects who believed in demonic possession as the cause of their mental illness were more likely to have internalized stigma and low SR ([31].

SR is the missed opportunity in African countries, particularly in Ethiopia. As per the authors' knowledge, there is only one study reporting the magnitude of SR among patients with mental illness in Ethiopia. However, it was limited to individuals with schizophrenia [28]. Therefore, this study is aimed at assessing the prevalence of SR and its predictors of people with bipolar disorders attending the outpatient department at AMSH. We hypothesized that low selfesteem, high internalized stigma, and unemployment were associated with low stigma resistance. The findings of this research work may have valuable clinical and policy implications by showing the level of stigma resistance and suggesting directions to design applicable strategies focusing on the promotion of stigma resistance and coping mechanisms of people with bipolar disorders. Furthermore, this study will be used as baseline information for further research works and community service programs.

\section{Methods}

2.1. Study Design and Period. This was an institutional-based cross-sectional study conducted from May $8^{\text {th }}, 2016$, to June $14^{\text {th }}, 2016$.

2.2. Study Setting. The current study was conducted at an outpatient department (OPD) of AMSH which is found in the capital city of Ethiopia, Addis Ababa. AMSH is the first hospital that started mental health service in Ethiopia since its establishment in 1930. The hospital provides services for people with psychiatric, neurological, substance use, and psychosocial problems in both outpatient and inpatient cares. Currently, the hospital has 18 OPDs serving for about 8,750 individuals with different mental health problems each month. The hospital has also 259 beds for inpatient service of people with severe mental illness, substance use, and emergency mental health conditions.

2.3. Source and Study Population. All bipolar patients who had a follow-up at the outpatient department of AMSH were the source population. Those who came for the follow-up during the data collection period were considered as the study population.

2.4. Inclusion and Exclusion Criteria. Clients with a confirmed clinical diagnosis of $\mathrm{BD}$ and age above or equal to 18 years during the data collection period were considered as eligible candidates for participation, whereas those who were on the acute episode and unable to speak or hear were excluded from the study.

2.5. Study Variables. The dependent variable was stigma resistance. Independent variables included sociodemographic factors (age, sex, ethnicity, religion, residence, marital status, educational status, and employment status), clinical factors (duration of illness, type of episode, duration of treatment, and number of hospitalization), and psychosocial factors (social support and self-esteem).

2.6. Sample Size Determination and Sampling Procedure. We used a single population proportion formula to estimate the minimum numbers of samples required for this study. Assumptions made for the sample size calculation were $50 \%$ prevalence of stigma resistance, $0.5 P, 1.96 Z$ (standard normal distribution), 95\% CI, $\alpha=0.05$, and a $10 \%$ nonresponse rate. Accordingly, a sample was found to be 423 .

Before the data collection, the total number of bipolar patients who visited the hospital in 2015 was identified from patients' records. Then, the average number of bipolar patients expected to visit the hospital during the data collection period was estimated to be 926 . Based on this, a sampling interval $(K)$ was determined by diving the total number of individuals with bipolar disorder expected to have 
a follow-up visit at the time of the data collection to the calculated sample size $(K=926 / 423 \approx 2)$. Finally, eligible individuals were interviewed for every 2 intervals based on the order of their clinical evaluation at the OPD.

2.7. Data Collection Procedures. Data were collected via faceto-face interviews using a pretested semistructured questionnaire consisting of sociodemographic factors, clinical characteristics, Oslo-3 Social Support Scale, Rosenberg Self-Esteem Scale, and internalized stigma of mental illness questionnaires.

All contents of the questionnaire were first prepared in English and translated to Amharic (the official language of the country) by Amharic-speaking linguist. Then, back translation to English was also done by mental health specialists to check its consistency. Prior to the actual data collection, the Amharic version of the questionnaire was pretested among 21 individuals with bipolar disorder who have never been included in the actual data collection. Based on the pretest result, a minor modification was done regarding the contents of the questionnaire, and expressions of some statements were rephrased to be easily understandable by the study participants.

Six data collectors (BSc psychiatric nurses) and two supervisors (MSc level mental health professionals) participated in the data collection after attending training regarding the content of the questionnaire and data collection procedures. Data collectors evaluated the eligibility of individuals and requested written consent after delivering a brief explanation regarding the objectives of the study. The interview was conducted at a separate private room prepared for this purpose around the waiting hall of AMSH.

2.8. Instruments. The outcome variable (stigma resistance) was evaluated using the stigma resistance subscale of the Internalized Stigma of Mental Illness (ISMI) scale [25]. The ISMI has 29-item questions with four possible response options. These 29 questions have been grouped into five subscales reflecting stigma resistance, alienation, stereotype endorsement, perceived discrimination, and social withdrawal. In this study, we used the stigma resistance subscale with five-item Likert scale questions $(1=$ strongly disagree, 2 = disagree, 3 $=$ agree, and $4=$ strongly agree) measuring a person's ability to resist or be unaffected by internalized stigma.

Each of the five questions of the stigma resistance scale has four response options scored with a reverse direction yielding a sum score ranges from 1 to 4 points. In the current study, Cronbach's alpha for stigma resistance was 0.632. A cut-off point at 2.5 and above on the mean item score of the stigma resistance subscale was applied to define moderate to high (referred to as "high") stigma resistance and less than 2.5 for low stigma resistance. This cut-off point has been applied in previous studies on stigma resistance $[9,28,32]$.

The social support level of the study participants was assessed by using the Oslo-3 Social Support Scale (OSSS-3). The tool has three-item questions collectively used to measure the accessibility of support patients will receive from their family, friends, and neighbors if needed [33]. Oslo-3 Social Support Scale is a validated tool to be used to measure social support level of individuals at clinical settings and community level. The tool has been used in different clinical- and community-based studies of African countries including Ethiopia. It has a total sum score ranging from 3 to 14 points. Based on the total sum score, the level of social support was categorized as poor, moderate, and strong social support with sum scores of 3-8, 9-11, and 12-14, respectively.

The self-esteem of individuals with bipolar disorders was evaluated using the Rosenberg Self-Esteem Scale. The tool contains 10-item questions with four possible response options (from strongly agree (1) through strongly disagree (4) for each. Based on the sum score, the level of self-esteem of the study participants was categorized as low self-esteem (a sum score of $<15$ ) and high self-esteem (a sum score of $\geq 15$ ) [34].

2.9. Data Processing and Analysis. The collected data were entered into EPI Info version 7 and exported to SPSS Windows version 20 program for analysis. Descriptive statistics (frequencies, tables, percentages, means, and standard deviation) were used to explain the sociodemographic characteristics, clinical variables, and level of SR of the study participants. Bivariable and multivariable analyses were applied to identify factors associated with SR. Accordingly, variables with $P$ values of less than 0.2 in the bivariable analysis were considered as candidates for further multivariable analysis to control possible cofounders. In the multivariable model, variables with $P$ values of less than 0.05 were considered as statistical predictors of SR. The odds ratio with a $95 \%$ confidence interval was used to measure the strength of the association.

2.10. Ethical Approval and Consent to Participation. This study was ethically approved by the Institutional Review Board (IRB) of the University of Gondar, and a supportive letter was obtained from Amanuel Mental Specialized Hospital. A written consent of participation was secured from each participant after delivering a brief explanation regarding the purpose and objectives of the study. Respondents were informed as they have full freedom to refuse and/or discontinue their participation at any time they want. Data collectors also disclosed that there will not any harm imposed towards respondents due to their willingness and/or refusal to participate. During the data collection, personal identifiers like name and phone numbers of respondents were not recorded. The collected data were kept confidential and used only for the purpose of the study.

\section{Results}

3.1. Sociodemographic Characteristics. From a total of 423 individuals invited to participate in this study, 418 participants completed the interview with a response rate of $98.81 \%$. The mean $( \pm$ SD) age of respondents was $34.29( \pm$ 10.36) years. Among respondents, $39.2 \%$ were within the age range of 25-34 years and more than half (53.3\%) were not married. About $51.5 \%$ of the participants were males and more than half $(55.0 \%)$ of them were orthodox in religion. Thirty-six percent of the study subjects were Amhara by their ethnicity and the majority (63.2\%) of them were employed. Nearly one-third (33.5\%) of bipolar patients attend secondary school education and $74.4 \%$ of them were from an urban area (Table 1). 
TABLE 1: Sociodemographic characteristics of people with bipolar disorder attending the outpatient department at Amanuel Mental Specialized Hospital, Addis Ababa, Ethiopia, $2016(n=418)$.

\begin{tabular}{|c|c|c|c|}
\hline Variables & Categories & Frequency & Percentage \\
\hline \multirow{4}{*}{ Age in years } & $18-24$ & 66 & 15.8 \\
\hline & $25-34$ & 164 & 39.2 \\
\hline & $35-44$ & 120 & 28.7 \\
\hline & $\geq 44$ & 68 & 16.3 \\
\hline \multirow{2}{*}{ Sex } & Male & 216 & 51.5 \\
\hline & Female & 202 & 48.3 \\
\hline \multirow{4}{*}{ Religion } & Orthodox & 230 & 55.0 \\
\hline & Muslim & 94 & 22.5 \\
\hline & Protestant & 82 & 19.6 \\
\hline & Others* & 12 & 2.9 \\
\hline \multirow{3}{*}{ Marital status } & Single & 223 & 53.3 \\
\hline & Divorced/widowed & 65 & 15.6 \\
\hline & Married & 130 & 31.1 \\
\hline \multirow{4}{*}{ Ethnicity } & Amhara & 151 & 36.1 \\
\hline & Oromo & 120 & 28.7 \\
\hline & Guragie & 75 & 17.9 \\
\hline & Others** & 72 & 17.2 \\
\hline \multirow{4}{*}{ Educational status } & Unable to read and write & 62 & 14.8 \\
\hline & Primary & 103 & 24.6 \\
\hline & Secondary & 140 & 33.5 \\
\hline & College and above & 113 & 27.0 \\
\hline \multirow{2}{*}{ Residency } & Rural & 107 & 25.6 \\
\hline & Urban & 311 & 74.4 \\
\hline \multirow{2}{*}{ Employment status } & Employed & 264 & 63.2 \\
\hline & Unemployed & 154 & 36.8 \\
\hline
\end{tabular}

${ }^{*}$ Catholic and Adventists. ${ }^{* *}$ Tigre, Silte, Gamo, Woleni, and Wolaiyta.

3.2. Clinical and Psychosocial Characteristics. Regarding the clinical characteristics of the participants, nearly one-third $(61.0 \%)$ of the participants developed BD before the age of 25 years and $37.6 \%$ of the reported that their illness had more than 10 years of duration. More than half (52.6\%) of individuals with $\mathrm{BD}$ had attended an outpatient treatment follow-up for less than six years. The largest proportion $(71.5 \%)$ of the study subjects had no family history of mental illness. Nearly seventy percent $(68.2 \%)$ of the participants had high selfesteem and $42.1 \%$ of them reported poor social support (Table 2).

3.3. The Prevalence of Stigma Resistance. More than half (56.9\%) of people with BD attending outpatient follow-up visits at AMSH scored below the mean score of a stigma resistance subscale of ISMIS with $95 \% \mathrm{CI}=51.9-61.6 \%$. Better SR level was observed among married individuals, individuals with good self-esteem, strong social support level, and better educational status.

3.4. Factors Associated with Stigma Resistance. To determine the association of independent variables with stigma resis- tance, bivariable and multivariable binary logistic regression analyses were performed. In the bivariable analysis, factors including employment status of the participants, marital status, educational level, current episode, number of previous episodes, internalized stigma, self-esteem, and social support were significantly associated with stigma resistance at a $P$ value less than 0.2 . These factors were entered into the multivariable logistic regression model to control confounding effects. However, in the multivariable analysis, being unemployed $(\mathrm{AOR}=1.65 ; 95 \% \mathrm{CI}=1.35-3.87)$, having a high level of internalized stigma $(\mathrm{AOR}=3.04 ; 95 \% \mathrm{CI}=1.83-5.05)$, and low self-esteem $\quad(\mathrm{AOR}=2.13 ; 95 \% \mathrm{CI}=1.72-6.76)$ were found as statistically significant predictors of stigma resistance at $P$ value less than or equal to 0.05 (Table 3 ).

\section{Discussion}

The finding of this study showed that the stigma resistance level of individuals with bipolar disorder at AMSH is low. More than half, of people with bipolar disorder attending outpatient follow-up visits at AMSH, scored below the mean score of stigma resistance subscale of ISMI. This figure is in 
TABle 2: Clinical and psychosocial factors of people with bipolar disorder attending the outpatient department at Amanuel Mental Specialized Hospital, Addis Ababa, Ethiopia, $2016(n=418)$.

\begin{tabular}{|c|c|c|c|}
\hline Variables & Categories & Frequency & Percentage \\
\hline \multirow{2}{*}{ Age at onset of illness } & $\leq 25$ years & 255 & 61 \\
\hline & $>25$ years & 163 & 39 \\
\hline \multirow{3}{*}{ Duration of illness } & Less than 5 years & 147 & 35.2 \\
\hline & $5-10$ years & 114 & 27.3 \\
\hline & $>10$ years & 157 & 37.6 \\
\hline \multirow{2}{*}{ Treatment duration } & $\leq 6$ years & 220 & 52.6 \\
\hline & $>6$ years & 198 & 47.4 \\
\hline \multirow{2}{*}{ Number of episodes } & $<2$ & 167 & 40 \\
\hline & $\geq 2$ & 251 & 60 \\
\hline \multirow{2}{*}{ Hospitalization history } & Yes & 218 & 52.2 \\
\hline & No & 200 & 47.8 \\
\hline \multirow{2}{*}{ Type of current episode } & Manic & 310 & 74.2 \\
\hline & Depressive & 108 & 25.8 \\
\hline \multirow{2}{*}{ Practice of traditional treatment } & Yes & 190 & 45.5 \\
\hline & No & 228 & 54.5 \\
\hline \multirow{2}{*}{ Family history of mental illness } & Yes & 119 & 28.5 \\
\hline & No & 299 & 71.5 \\
\hline \multirow{2}{*}{ Previous suicidal attempt } & Yes & 144 & 34.4 \\
\hline & No & 274 & 65.6 \\
\hline \multirow{2}{*}{ Medication discontinuation } & Yes & 233 & 55.7 \\
\hline & No & 185 & 44.3 \\
\hline \multirow{3}{*}{ Social support level } & Poor & 176 & 42.1 \\
\hline & Moderate & 148 & 35.4 \\
\hline & Strong & 94 & 22.5 \\
\hline \multirow{2}{*}{ Self-esteem } & Low self-esteem & 133 & 31.8 \\
\hline & High self-esteem & 285 & 68.2 \\
\hline
\end{tabular}

line with studies done across 13 countries in Europe (59.7\%) [7] and Iran (57.49\%) [29]. However, the finding of the current study was higher as compared to a study conducted in northern India which reported that $28.6 \%$ of bipolar patients had low stigma resistance [35]. The possible explanation for the discrepancy of such findings might be due to the differences in population characteristics and sample sizes (the Indian study used 185 patients with bipolar disorder). The collectivism culture of the Ethiopia population might play a role to resist stigma as a result of a better social support system and community reengagement. On the other hand, a study conducted in Turkey (62.2\%) [30] showed a better stigma resistance of people with bipolar disorder as compared to the finding of our study. Differences in the cultural and sociodemographic characteristics of the study participants might play a role in the difference of these findings. For example, low educational status and unemployment status of individuals in Ethiopia may be possible reasons for the lower stigma resistance ability of the study participants. High educational status such as university education may contrib- ute to having high stigma resistance by helping the people not to apply the devaluing judgments to themselves [36, 37].

The second objective of this study was to identify predictors of SR among individuals with bipolar disorder. Participants who were currently unemployed were 1.65 times more likely to have low SR as compared to those who were employed. This finding is in line with other studies [38, 39]. The possible explanation for this discrepancy might be due to the fact that employed individuals often have better confidence and become mentally satisfied as a result of their reliance. This suggests a need to develop strategies to have high stigma resistance by enhancing the employment status of individuals with mental health problems.

Bipolar patients who had a higher internalized stigma were more than three times more likely to have lower stigma resistance as compared to their counterparts. This finding is supported by previous studies that reported higher stigma resistance was related to lesser internalized stigma [32, 40]. This might possibly be explained by the fact that patients who had high stigma resistance may not apply negative 
TABLE 3: Bivariable and multivariable analyses of stigma resistance among people with bipolar disorder attending the outpatient department at Amanuel Mental Specialized Hospital, Addis Ababa, Ethiopia, $2016(n=418)$.

\begin{tabular}{|c|c|c|c|c|c|}
\hline \multirow{2}{*}{ Variables } & & \multicolumn{2}{|c|}{ Stigma resistance } & \multirow{2}{*}{ COR $(95 \% \mathrm{CI})$} & \multirow{2}{*}{ AOR $(95 \% \mathrm{CI})$} \\
\hline & & Good & Poor & & \\
\hline \multirow{2}{*}{ Employment status } & Employed $^{\mathrm{a}}$ & 101 & 163 & 1.00 & \\
\hline & Unemployed & 79 & 75 & $1.69(1.14-2.54)$ & $1.65(1.35-3.87)$ \\
\hline \multirow{3}{*}{ Marital status } & Single & 97 & 126 & $1.61(0.90-2.89)$ & $1.45(0.88-2.39)$ \\
\hline & Divorced/widowed & 62 & 68 & $1.91(1.02-3.56)$ & $0.57(0.29-1.08)$ \\
\hline & Married $^{\mathrm{a}}$ & 21 & 44 & 1.00 & 1.00 \\
\hline \multirow{4}{*}{ Educational status } & Unable to read and write & 34 & 28 & $1.90(1.102-3.56)$ & $1.54(0.76-3.12)$ \\
\hline & Primary & 42 & 61 & $1.02(0.63-1.86)$ & $1.02(0.57-1.84)$ \\
\hline & Secondary & 60 & 80 & $1.18(0.71-1.95)$ & $1.09(0.63-1.88)$ \\
\hline & College and above $^{\mathrm{a}}$ & 44 & 69 & 1.00 & 1.00 \\
\hline \multirow{2}{*}{ Current episode } & Manic $^{\mathrm{a}}$ & 141 & 169 & 1.00 & 1.00 \\
\hline & Depressive & 39 & 69 & $0.68(0.43-1.06)$ & $1.24(0.74-2.06)$ \\
\hline \multirow{2}{*}{ Number of episodes } & $<2$ years $^{\mathrm{a}}$ & 64 & 103 & 1.00 & 1.00 \\
\hline & $\geq 2$ years & 116 & 135 & $0.72(0.48-1.08)$ & $0.74(0.47-1.17)$ \\
\hline \multirow{2}{*}{ Internalized stigma } & Yes & 112 & 202 & $2.94(0.18-0.48)$ & $3.04(1.83-5.05)$ \\
\hline & $\mathrm{No}^{\mathrm{a}}$ & 68 & 36 & 1.00 & 1.00 \\
\hline \multirow{2}{*}{ Self-esteem } & Low & 63 & 117 & $1.29(0.85-1.96)$ & $2.13(1.72-6.76)$ \\
\hline & $\operatorname{High}^{\mathrm{a}}$ & 70 & 168 & 1.00 & 1.00 \\
\hline \multirow{3}{*}{ Social support level } & Poor & 82 & 94 & $1.77(1.05-2.98)$ & $1.40(0.02-3.20)$ \\
\hline & Moderate & 67 & 81 & $1.68(0.98-2.88)$ & $1.75(0.98-3.09)$ \\
\hline & Strong ${ }^{\mathrm{a}}$ & 31 & 63 & 1.00 & 1.00 \\
\hline
\end{tabular}

${ }^{a}$ Reference variable. OR: crude odds ratio; AOR: adjusted odds ratio.

stereotypes such as devaluation, shame, secrecy, and withdrawal $[9,25,41]$. The collaboration between health sectors and community support group is needed to minimize internalized stigma and improve the stigma resistance capacity of bipolar patients.

Finally, the study participants who had low self-esteem were $2.13(\mathrm{AOR}=2.13 ; 95 \% \mathrm{CI}=4.72-8.76)$ times more likely to have low SR. A study in northern India also stated that there is a positive correlation between stigma resistance and self-esteem in patients with mental illness [9]. Low selfesteem reduces the patient's capacity of stigma resistance by applying negative stereotype attitudes about themselves [42]. Therefore, promotion and strengthening of positive self-esteem can be considered as a strategy to improve the SR capacity of people with BD.

4.1. Limitations of the Study. This study may have limitations. First, the study was conducted among individuals with bipolar disorder having outpatient follow-up visit and might not be representative of individuals with mental health problems other than bipolar disorder. Second, as far as the study was conducted at a hospital level, bipolar patients who did not start a treatment have never been addressed. Third, the cross-sectional nature of the study design might not show the cause and effect relationships of study variables. Fourth, the data collection method was a face-to-face interview which might led individuals to respond in socially acceptable ways (social desirability and recall bias). Finally, since the instrument we have used to assess SR is not validated in Amharic language (local language of our study area), it might underor overestimate the SR.

4.2. Conclusion and Recommendation. The finding of this study showed that more than half of individuals with bipolar disorder had low stigma resistance. Stigma reduction programs focusing on improving the self-esteem and minimizing the internalized stigma were better to be implemented by stakeholders to increase the stigma resistance of patients with bipolar disorder. Moreover, mental health information dissemination regarding the community support and reengagement of people with bipolar disorder is highly recommended. Validitating the stigma resistance subscale of the internalized stigma of mental illness in local language is recommended for researchers.

\section{Abbreviations}

AMSH: Amanuel Mental Specialized Hospital

AOR: Adjusted odds ratio

BD: $\quad$ Bipolar disorder

BSc: Bachelor of Science

CI: $\quad$ Confidence interval

COR: Crude odds ratio

ISMI: Internalized stigma of mental illness 
MSc: $\quad$ Masters of Science

OPD: Outpatient departments

OSSS-3: Oslo-3 Social Support Scale

SD: $\quad$ Standard deviation

SR: $\quad$ Stigma resistance

WHO: World Health Organization.

\section{Data Availability}

The datasets generated and/or analyzed during the current study are not publicly available due to some privacy reasons, but part of the row datasets will be available from the corresponding author on reasonable request.

\section{Ethical Approval}

This study was ethically approved by the Institutional Review Board (IRB) of the University of Gondar, and a supportive letter was obtained from Amanuel Mental Specialized Hospital.

\section{Consent}

A written consent of participation was secured from each participant after delivering a brief explanation regarding the purpose and objectives of the study. Respondents were informed as they have full freedom to refuse and/or discontinue their participation at any time they want. Data collectors also disclosed that there will not any harm imposed towards respondents due to their willingness and/or refusal to participate. During the data collection, personal identifiers like name and phone numbers of respondents were not recorded. The collected data were kept confidential and used only for the purpose of the study.

\section{Disclosure}

Since this study was done for educational purposes, the funder (University of Gondar) has no role in the publication and use of this study.

\section{Conflicts of Interest}

All authors declare that they have no competing interests.

\section{Authors' Contributions}

NAE originated the idea and participated in the proposal development, questionnaire development, data collection, analysis, and manuscript writing. EYA and ZB took more roles in the data collection, software analysis, manuscript draft preparation, and revision. All authors read the final version of the manuscript and approved this version of the manuscript to be considered for publication.

\section{Acknowledgments}

We would like to acknowledge the University of Gondar and Amanuel Specialized Mental Hospital for the ethical approval. Our gratitude also goes to the study subjects for their voluntary participation. Our gratitude also goes to the staff of Amanuel Mental Specialized Hospital for their valuable contribution to the accomplishment of this research work. Last but not least, our heartfelt thanks go to the supervisors and data collectors for their admirable endeavor during the data collection.

\section{References}

[1] F. Edition, Diagnostic and Statistical Manual of Mental Disorders, American Psychiatric Publishing, Arlington, 2013.

[2] K. R. Merikangas, R. Jin, J.-P. He et al., "Prevalence and correlates of bipolar spectrum disorder in the world mental health survey initiative," Archives of General Psychiatry, vol. 68, no. 3, pp. 241-251, 2011.

[3] R. J. Baldessarini, E. Vieta, J. R. Calabrese, M. Tohen, and C. L. Bowden, "Bipolar depression: overview and commentary," Harvard Review of Psychiatry, vol. 18, no. 3, pp. 143-157, 2010.

[4] C. L. Bowden, "Bipolar pathophysiology and development of improved treatments," Brain Research, vol. 1235, pp. 92-97, 2008.

[5] L. L. Judd and H. S. Akiskal, "The prevalence and disability of bipolar spectrum disorders in the US population: re-analysis of the ECA database taking into account subthreshold cases," Journal of Affective Disorders, vol. 73, no. 1-2, pp. 123-131, 2003.

[6] K. R. Merikangas, H. S. Akiskal, J. Angst et al., "Lifetime and 12-month prevalence of bipolar spectrum disorder in the National Comorbidity Survey replication," Archives of General Psychiatry, vol. 64, no. 5, pp. 543-552, 2007.

[7] E. Brohan, D. Gauci, N. Sartorius, G. Thornicroft, and Group GES, "Self-stigma, empowerment and perceived discrimination among people with bipolar disorder or depression in 13 European countries: the GAMIAN-Europe study," Journal of Affective Disorders, vol. 129, no. 1-3, pp. 56-63, 2011.

[8] E. Brohan, R. Elgie, N. Sartorius, G. Thornicroft, and Group GES, "Self-stigma, empowerment and perceived discrimination among people with schizophrenia in 14 European countries: the GAMIAN-Europe study," Schizophrenia Research, vol. 122, no. 1-3, pp. 232-238, 2010.

[9] I. Sibitz, A. Unger, A. Woppmann, T. Zidek, and M. Amering, "Stigma resistance in patients with schizophrenia," Schizophrenia Bulletin, vol. 37, no. 2, pp. 316-323, 2011.

[10] N. Ellison, O. Mason, and K. Scior, "Bipolar disorder and stigma: a systematic review of the literature," Journal of Affective Disorders, vol. 151, no. 3, pp. 805-820, 2013.

[11] L. D. Hawke, V. Velyvis, and S. V. Parikh, "Bipolar disorder with comorbid anxiety disorders: impact of comorbidity on treatment outcome in cognitive-behavioral therapy and psychoeducation," International journal of bipolar disorders, vol. 1, no. 1, p. 15, 2013.

[12] N. Rüsch and G. Thornicroft, "Does stigma impair prevention of mental disorders?," The British Journal of Psychiatry, vol. 204, no. 4, pp. 249-251, 2014.

[13] M. C. Angermeyer and S. Dietrich, "Public beliefs about and attitudes towards people with mental illness: a review of population studies," Acta Psychiatrica Scandinavica, vol. 113, no. 3, pp. 163-179, 2006.

[14] J. C. Phelan, E. J. Bromet, and B. G. Link, "Psychiatric illness and family stigma," Schizophrenia Bulletin, vol. 24, no. 1, pp. 115-126, 1998.

[15] Organization WH, The World Health Report 2001: Mental Health: New Understanding, World Health Organization, New Hope, 2001. 
[16] D. A. Perlick, D. J. Miklowitz, B. G. Link et al., "Perceived stigma and depression among caregivers of patients with bipolar disorder," The British Journal of Psychiatry, vol. 190, no. 6, pp. 535-536, 2007.

[17] T. Shibre, A. Negash, G. Kullgren et al., "Perception of stigma among family members of individuals with schizophrenia and major affective disorders in rural Ethiopia," Social Psychiatry and Psychiatric Epidemiology, vol. 36, no. 6, pp. 299-303, 2001.

[18] A. C. Watson, P. Corrigan, J. E. Larson, and M. Sells, "Selfstigma in people with mental illness," Schizophrenia Bulletin, vol. 33, no. 6, pp. 1312-1318, 2007.

[19] P. W. Corrigan and D. Rao, "On the self-stigma of mental illness: stages, disclosure, and strategies for change," The Canadian Journal of Psychiatry, vol. 57, no. 8, pp. 464-469, 2012.

[20] P. W. Corrigan, A. C. Watson, and L. Barr, "The self-stigma of mental illness: implications for self-esteem and self-efficacy," Journal of Social and Clinical Psychology, vol. 25, no. 8, pp. 875-884, 2006.

[21] P. T. Yanos, D. Roe, K. Markus, and P. H. Lysaker, "Pathways between internalized stigma and outcomes related to recovery in schizophrenia spectrum disorders," Psychiatric Services, vol. 59, no. 12, pp. 1437-1442, 2008.

[22] A. S. Masten, "Resilience in children threatened by extreme adversity: frameworks for research, practice, and translational synergy," Development and Psychopathology, vol. 23, no. 2, pp. 493-506, 2011.

[23] S. K. Reddy, J. Thirthalli, N. K. Channaveerachari et al., "Factors influencing access to psychiatric treatment in persons with schizophrenia: a qualitative study in a rural community," Indian Journal of Psychiatry, vol. 56, no. 1, pp. 54-60, 2014.

[24] A. Hofer, F. Post, S. Pardeller et al., "Self-stigma versus stigma resistance in schizophrenia: associations with resilience, premorbid adjustment, and clinical symptoms," Psychiatry Research, vol. 271, pp. 396-401, 2019.

[25] J. B. Ritsher, P. G. Otilingam, and M. Grajales, "Internalized stigma of mental illness: psychometric properties of a new measure," Psychiatry Research, vol. 121, no. 1, pp. 31-49, 2003.

[26] R. L. Firmin, P. H. Lysaker, J. H. McGrew, K. S. Minor, L. Luther, and M. P. Salyers, "The Stigma Resistance Scale: a multi-sample validation of a new instrument to assess mental illness stigma resistance," Psychiatry Research, vol. 258, pp. 37-43, 2017.

[27] C. Campbell and H. Deacon, "Unravelling the contexts of stigma: from internalisation to resistance to change," Journal of Community \& Applied Social Psychology, vol. 16, no. 6, pp. 411-417, 2006.

[28] B. B. Bifftu, B. A. Dachew, and B. T. Tiruneh, "Stigma resistance among people with schizophrenia at Amanuel Mental Specialized Hospital Addis Ababa, Ethiopia: a cross-sectional institution based study," BMC Psychiatry, vol. 14, no. 1, p. 259,2014

[29] G. Sadighi, M. R. Khodaei, F. Fadai, A. Mirabzadeh, and A. Sadighi, "Self stigma among people with bipolar-I disorder in Iran," Iranian Rehabilitation Journal, vol. 13, no. 1, p. 32, 2015.

[30] G. Sarısoy, Ö. F. Kaçar, O. Pazvantoğlu et al., "Internalized stigma and intimate relations in bipolar and schizophrenic patients: a comparative study," Comprehensive Psychiatry, vol. 54, no. 6, pp. 665-672, 2013.

[31] A. W. Ibrahim, Y. M. Mukhtar, P. K. Sadique et al., "A facilitybased assessment of internalized stigma among patients with severe mental illnesses in Maiduguri, North-Eastern Nigeria," International Neuropsychiatric Disease Journal, vol. 6, no. 1, pp. 1-11, 2016.

[32] Y. W. Lau, L. Picco, S. Pang et al., "Stigma resistance and its association with internalised stigma and psychosocial outcomes among psychiatric outpatients," Psychiatry Research, vol. 257, pp. 72-78, 2017.

[33] T. Abiola, O. Udofia, and M. Zakari, "Psychometric properties of the 3-item Oslo Social Support Scale among clinical students of Bayero University Kano, Nigeria," Malaysian Journal of Psychiatry, vol. 22, no. 2, pp. 32-41, 2013.

[34] R. W. Robins, H. M. Hendin, and K. H. Trzesniewski, "Measuring global self-esteem: construct validation of a singleitem measure and the Rosenberg Self-Esteem Scale," Personality and Social Psychology Bulletin, vol. 27, no. 2, pp. 151-161, 2016.

[35] S. Grover, N. Hazari, J. Aneja, S. Chakrabarti, and A. Avasthi, "Stigma and its correlates among patients with bipolar disorder: a study from a tertiary care hospital of North India," Psychiatry Research, vol. 244, pp. 109-116, 2016.

[36] A. Diaz-Caneja and S. Johnson, "The views and experiences of severely mentally ill mothers-a qualitative study," Social Psychiatry and Psychiatric Epidemiology, vol. 39, no. 6, pp. 472482, 2004.

[37] E. Edwards and S. Timmons, "A qualitative study of stigma among women suffering postnatal illness," Journal of Mental Health, vol. 14, no. 5, pp. 471-481, 2009.

[38] J. D. Livingston and J. E. Boyd, "Correlates and consequences of internalized stigma for people living with mental illness: a systematic review and meta-analysis," Social Science \& Medicine, vol. 71, no. 12, pp. 2150-2161, 2010.

[39] C. Krajewski, G. Burazeri, and H. Brand, "Self-stigma, perceived discrimination and empowerment among people with a mental illness in six countries: Pan European stigma study," Psychiatry Research, vol. 210, no. 3, pp. 1136-1146, 2013.

[40] P. H. Lysaker, D. Roe, and P. T. Yanos, “Toward understanding the insight paradox: internalized stigma moderates the association between insight and social functioning, hope, and self-esteem among people with schizophrenia spectrum disorders," Schizophrenia Bulletin, vol. 33, no. 1, pp. 192-199, 2006.

[41] G. Gerlinger, M. Hauser, M. De Hert, K. Lacluyse, M. Wampers, and C. U. Correll, "Personal stigma in schizophrenia spectrum disorders: a systematic review of prevalence rates, correlates, impact and interventions," World Psychiatry, vol. 12, no. 2, pp. 155-164, 2013.

[42] P. T. Yanos, D. Roe, M. L. West, S. M. Smith, and P. H. Lysaker, "Group-based treatment for internalized stigma among persons with severe mental illness: findings from a randomized controlled trial," Psychological Services, vol. 9, no. 3, pp. 248258, 2012. 